\title{
CONTEMPORARY FISHERIES RISKS AND SME RESILIENCE DUTCH FISHING VESSEL (RE)DESIGNING 1988-2018
}

\author{
Frans Veenstra ${ }^{1}$ \\ Hendrik Kramer ${ }^{2}$ \\ 1) Delft University of Technology, Netherlands \\ 2) Foundation Masterplan Sustainable Fisheries, Netherlands
}

\begin{abstract}
The North Sea flatfish fisheries can be characterized by small, family owned enterprises (SME), where the fishermen have a decisive voice in (re)designing and adapting to sociotechnical system capacity, safety-wellbeing and resilient business performances. In particular, the Dutch safety- and sustainability awareness reflect on engineering (reliability) and business models. Where maritime resilience goes further than a mere socio-organizational approach on safety consequences and recovery from mishap and disaster. Since the 80 s the Dutch fishing vessels had to adapt to three major socio-political changes, at the same time becoming key (re)design drivers: from traditional to Safe \& Health Environment (SHE; Kindunos; safetyintegrated re-design), from SHE to Corporate Social Responsibility (CSR; MDV-1; disruptive new design) and currently from sustainable to integration of the Circular Economy Principles (CE; prospective CE-(re)design concepts). On existing vessels the required safety-and sustainable modifications came with very high transition costs, especially under conditions of the 2008 economic crisis. This severely hampered the ability of individual SME's to invest in mid-life upgrades, let alone in disruptive new buildings. The new socio-political challenges dictate change in (re)design approaches, in which sound safety aspects stay consistent and vital. In order to remain flexible and resilient to future fishery system changes, the fishing vessel design process must become more transparent and already start at conceptual level. Firstly with identification of future-proof design aims and sound business models, rather than further restrictive detailing and extensive quantification of current performance indicators. Such an effort requires disruptive design approaches at corporate- and sector level rather than adaptation at a strict organizational level. However, the resilience engineering essential abilities are a good start-up integrating multiple- sustainability change drivers. It requires an integration of fisheries engineering expertise, sectoral and public support and new cyclic innovation strategies. Such a integrative top-down/bottom-up (design)cooperation facilitate foresight on future SME behavior and viable exploitation of fishing vessels in a life cycle approach; making them less dependent on constantly changing socio-economic market mechanisms for the short and medium term as well as socio-political change drivers on the long term.
\end{abstract}

Keywords: CE-sustainability, Fishing, Safety

(C) 2019 Veenstra \& Kramer. This is an Open Access article distributed under the terms of the Creative Commons AttributionNonCommercial 4.0 International License (http://creativecommons.org/licenses/by-nc/4.0), permitting all non-commercial use, distribution, and reproduction in any medium, provided the original work is properly cited.

ISBN: 978-91-88898-41-8

DOI: https://doi.org/10.15626/rea8.01 


\section{DUTCH FISHERIES AND CONTEMPORARY (SAFETY) RISKS 1988 -2018}

The North Sea flatfish fisheries, beam trawling can be characterized by small, family owned enterprises (SME), where the fishermen have a decisive voice in (re)designing and adjusting the socio-technical fishery system capacity regarding safety \& wellbeing and cost-efficiently adapting towards future-proof business models. Today, the overall safety regulations are well institutionalized and applied on existing fishing vessels and new buildings; viable and transparent through laws, accident investigations and structural risk assessments. However, when it comes to personal safety in the sense of well-being, the improvements have been more a matter of personal experiences and wishes. Depending on the vocational skill of skipper/crew, but also on the age of the vessel and maintenance. Additionally, the evolving climate rules and decreasing fishing grounds (offshore energy, traffic lanes, nature parks) are changing the SME/sector behavior, workload and stress. On board cameras/remote VMS systems and ad random high seas inspections are aggravating the resilience business performance. This started already in the 90's with practical and scientific challenges to what extent SMEs could anticipate these developments through redesigning? Because at the time, the Netherlands had a new, modern fishing fleet and the fishermen weren't planning new designs. However EU politically driven, the researchers were asked to investigate the safety and occupational accidents (1982-1988) and to develop cost-efficient (partial) solutions. The safety projects were conducted by applied fishery researchers and fundamental safety researchers, resp. RIVO (a.o. Frans Veenstra) and TU Delft (a.o. John Stoop) [1-5]. Always in close cooperation with the SME's, fishermen (organizations) and ministries. The outcome was a safety-integrated redesign of existing beamers with practical solutions as well as the development of a scientific methodology to deal with personal safety in the (re)design process of fishing vessels. Basically Kindunos is a problem solving oriented approach with sound safety-concepts and viable (partial) solutions. This approach provides separate categories for SHE solutions on the level of the local workplace, adaptation of the vessel design and changes in the area of management and vocal training. Based on the new resilience problem solving methodology, the fishery research was extended with additional quality aspects, fish products and better footprints (RIVO, beamer-2000, trawler 2000 redesigns) with safety as strategic asset [6-9]. Since 2000, the Dutch fishing vessels had to adapt to new socio-political changes: from SHE to Corporate Social Responsibility (CSR; MDV) and today from Sustainable to Circular Economy Principles (CE; climate-requirements) [10]. The new (re)design drivers and requirements towards vessel adaptations grew in magnitude. Based on the derivative safetyintegrated Beamer-2000 redesign concept, new disruptive, sustainable-integrated and foreseeable, circular economy-integrated new designs are urgently needed. So that the SME's and fishermen can cost-efficiently adapt and protect their future profits. With the launch of the disruptive new MDV-1 pilot vessel (2015), the triple-P sustainable design drivers (People, Planet, Profit) have been fully integrated. The linear Kindunos methodology had been accordingly adapted with these triple-P key resilience factors. Since 2017, the next sustainability steps have to be taken in consideration towards a more climate-driven approach with integration of the Circular Economy principles. Additionally, a new design tool has been developed under the umbrella of the TU Delft PhD study "Sustainability and the fishing vessel design process, Veenstra". In which the CE-operational actors, current political-climate structures and public perception must become the key resilience characteristics. Based on the Kindunos solution-matrices and disruptive MDV-1 (re)design experiences, the 3 CEDI-indexsolution matrices have become the new, supportive CE (re)design tool with gradual development of foreseeable, climate-integrated (re)designs, even towards autonomous fishing vessels without a crew (Horizon 2050, carbon free, autonomous, free of occupational accidents). 


\section{SHE contemporary safety risks 80/90s: Kindunos methodology \& derivative redesign}

In the $80 / 90$ s a safety-resilience problem solving study and Beamer-2000 projects were conducted by RIVO and TU Delft with intensive cooperation with SME/ fishermen (organizations). At the time, the research goal was to reconsider the existing 70/80s beamer designs. Firstly from an integral safety point of view, later also from an integral quality point of view (workplaces, product, footprint). This resulted in the 2000 safety-and quality requirements, validated in conceptual redesigns, Beamer2000 [6] Political driven, the SHE aspects became the redesign and operational change drivers for more safe and sound working conditions on beamers. Hard and vague redesign requirements were clarified and through the new safety problem solving approach and safety integration matrices redesign [3] recommendations could be cost-efficiently given. These matrices dealt with accident and labor analysis and potential (partial) solutions, on the level of workplaces as well as overallredesign (Figure 1). Which was useful for devising a safety integrated approach in (re)designing, limiting/avoiding new hazards or side effects in the (re)design process and introduction of innovations. With the safety-matrices and preliminary design, the beamer SHE-issues became very accessible for the safety- and fishery researchers as well as SMEs and commercial designers. Many scientifically exchanges of views and international cooperation took place, esp. with input of master students and contributions on (safety) symposia, especially in Norway (Marintek), France (Ifremer/CEASM) and the UK (Seafish Authority). The new derivative design results were published in fishery magazines and (inter)national journals [9]

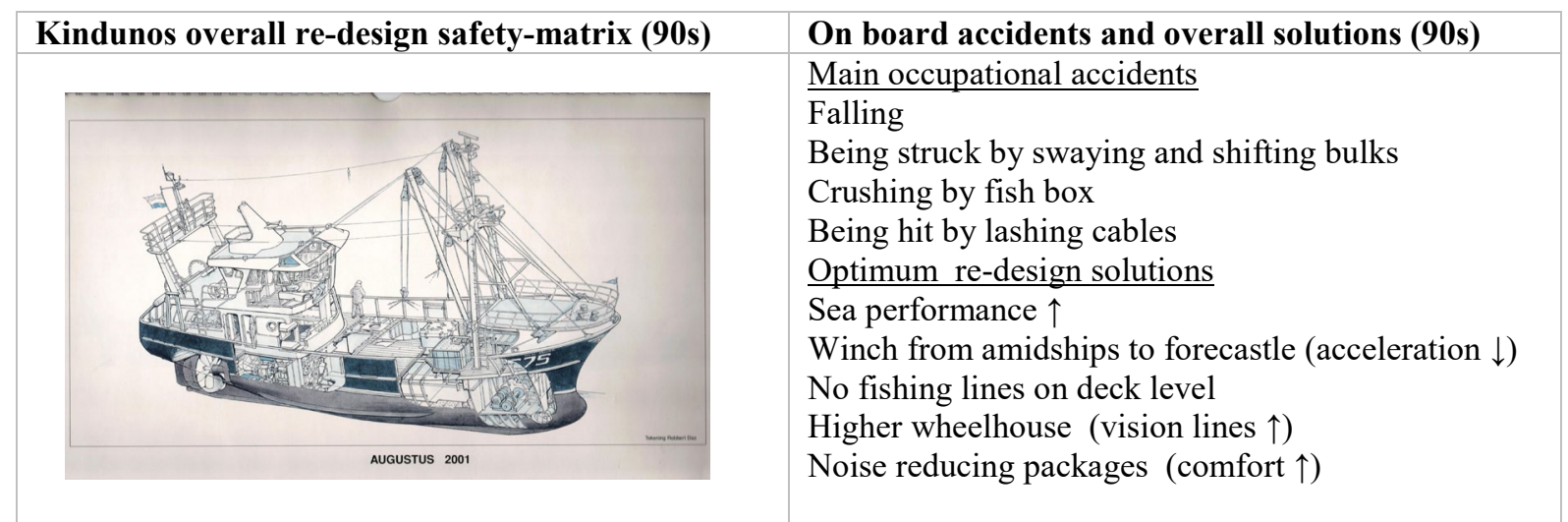

Figure 1. Beamer most common type of accidents and beamer-2000 re-design solutions 
By regularly knowledge transfer, the fishery safety and quality awareness of the Dutch fishing sector have considerably been increased. Although at the $90 \mathrm{~s}$, the vessel sea performance couldn't be modified as well as replacing the winch to the forecastle deck, due to too high refit-costs. This means that the most common types of occupational accidents are still occurring and only in new buildings can be foreseen. However nowadays, interactive risk assessment web tools (OiRA, EU mandatory) are obliged for on board usage. With such a tool, an appropriate risk assessment process and safety awareness take constantly place. Starting with the identification and evaluation of workplace risks and taking preventive (resilience) actions with transparent monitoring and reporting.

\section{CSR contemporary (safety) risks 2008-2015: MDV-1 pilot vessel \& disruptive design}

Between 1995-2008, there were next to nothing follow-ups of the Beamer2000 and Trawler2000 projects and only a few new buildings. Although the basic beamer design concept was the same, many beamer 2000 partial solutions have been integrated with respect to safe gear handling, lesser workload and higher comfort. Also risk assessments are taken place and maritime occupational accidents are being (inter)nationally reported (Sector raad Visserij, CHIRP maritime feedback). On sectoral level, there is a national safety consulting group (Arbo \& Veiligheid) with beamer and trawler representatives and regular newsletters. Since 2000, the changing political structures and society required increasing Corporate Social Responsibilities (CSR) of the North Sea fisheries (license2fish). Due to increasing marine fuel prices and low fish prices, the SME/fishermen earnings came severely under pressure. On the aging vessels the required modifications meant very high transition costs. Aggravated by the 2008 economic crisis, none of the SMEs could afford this and adaptations with respect to stricter eco-regulations (socio-political drivers). This severely hampered the ability of individual SME's to invest in mid-life upgrades, let alone in new buildings. Then on sectoral level, the foundation Masterplan Sustainable Fisheries was established (MDV, 2006-present), to design and launch an innovative, sustainable pilot fishing vessel, the MDV-1 stern twin rig trawler (2015-present) [11]. Far-reaching challenges, triggered by the CSR political and economic changes and firstly mentioned by an innovation-minded skipper-owner (2010). Instead of further derivative redesigns and ad-hoc (partial) energy-saving solutions, disruptive new designs were urgently needed with SHE as a strategic asset, to attract/keep good fishermen on board. Additionally becoming more resiliently for the upcoming uncertainties and predictabilities and also gaining more public support. To anticipate these new developments, the aging fleet (average $>25 \mathrm{yrs}$ ) must be replaced by more innovative fishing vessels. Where future-proof business models are the flywheel of the sustainable progress: good for the fishermen (People), good for the shipbuilding industry(Profit) as wells as good for the marine and public environment (Planet).The lean MDV team consisted of multidisciplinary expertise with representative fishery, financial, legal and research experts. Based on his Beamer-2000 experiences, Frans Veenstra became the MDV innovation manager (2013-present), in resilience terms: the Subject Matter Expert (SME). Together with the MDV-1 skipper/co-owner Hendrik Kramer, they bridged the gap between theory and practice. From research perspective, the MDV project was an excellent chance to further implement the Kindunos systems engineering approach and to fully solve the Beamer-2000 safety shortcomings (Figure 1,Figure 2). 


\begin{tabular}{|l|l|}
\hline Beamer SHE shortcomings (90s) & MDV-1 including the Beamer-2000 SHE solutions (2015) \\
\hline Falling and comfort & Good sea performance, good noise and fish processing amidships \\
\hline Swaying nets, hit by lashing cables & Gear handling astern, no fishing lines over deck, good vision lines \\
\hline Shifting bulks/netting/objects & Retaining devices \\
\hline $\begin{array}{l}\text { Unsafe working conditions and heavy } \\
\text { workload }\end{array}$ & $\begin{array}{l}\text { Clear deck layout, deck cranes and further mechanization (processing } \\
\text { deck, fish hold) }\end{array}$ \\
\hline
\end{tabular}

Figure 2. Beamer SHE shortcomings and MDV-1 new design solutions

From CSR perspectives, the SME economy activities must be substantially improved (Profit) with more respect to the on board social factors/human behaviour (People) and to comply with the current socio-political structures (Planet) and viable public support (Publicperception). This meant a further integration of these design drivers with challenging MDV design goals: $80 \%$ energy saving, hence substantial $\mathrm{CO} 2$ emission reduction, provensustainability with acceptable investments, excellent North Sea working platform and sound knowledge transfer (licence2fish).Based on 3 pre-designs (Hoekman Shipbuilding, Maaskant/Damen Shipbuilding, Padmos Shipbuilding; 2012), the MDV-1 feasibility could be sufficiently clarified, SME affordable and with reliable green technologies [23-24]. Generally speaking SMEs couldn't afford 'trial\&error' projects; too risky from business performance perspective. To achieve the MDV goals in practice, five key innovation pillars were costefficiently developed to:

- optimize ship's motion with lower resistance (hullform, general arrangement)

- substantially reduce energy-consumption (installations, lightweight construction)

- increase safety and decrease workload (gear handling, (semi-) automation fish processing)

- improve the quality of fish and semi-automated fish cool-chain (shorter, fish2dish);

- apply sustainable fishing gears and recyclable construction materials (selective gear, composites)

For the required business model and economic benefits over the lifecycle, solutions had to be found to solve some conflicts of interest. E.g. to improve the North Sea performances, a larger vessel is required while for the business model one must keep the new investments rather low, through a smaller vessel. 
Also a slender hullform and spacious workdecks must integrate sufficient carrying capacity for the North Sea operational profiles to land good quality fish. This have been solved by extensive CFD hullform simulations (digital towing tank modelling), resulting in the $30 \mathrm{~m}$ MDV-1 pilot vessel with the best hydrodynamic features within the fishery constraints. The investment for this vessel was 4.5 Meuro, at least $40 \%$ cheaper than comparable $40 \mathrm{~m}$ beamers. After three years of fishing the ROI is $8-10$ yrs., due to a sound economic business model (fuel and maintenance cost $<30 \%$ vs $60 \%$ for aging beamers). After the first sea trials, the stakeholders could conclude that the technical targets were fully realised, esp. seaworthiness, energy-saving, gear-and fish handling, low noise levels and good vision lines (table 2). However, the operational fishery targets were not reached yet due to prototype shortcomings (twinrig pulse fishing gears, semi-automated fish processing equipment). The prototypes are being further developed in the MDV-1 research period, phase 4 (2016-present). From the original Beamer-2000 redesign point of view, the MDV-1 new design became the intrinsic safe Beamer-2000, where in the 90s, Frans Veenstra and John Stoop were aiming at. The socio-economical market mechanism and societal developments of a higher order dictated the changes and renewed business resilience approach. Beside the safety shortcomings more operational quality aspects have been addressed. The fact that MDV-1 became the KNVTS "Ship of the Year 2016" and the MDV foundation have been awarded as the most innovative sustainable SME on Urk, demonstrated that the new MDV approach/design (process) was very successful [11]. SME business models, reliable engineering and system safety were the essential resilience characteristics, anticipating unfavorable business models due to foreseeable higher fuel prices, lower fish prices and CO2 taxes. With the MDV-1 design experiences, the next sustainability step can be taken to anticipate stricter climate regulations and new social-political structures, the Circular Economy principles (CE). However, these general CE-principles have firstly to be translated in pre-design requirements towards more carbon-free vessels, far-reaching recyclability and mere happy people on-board, hence intrinsic safe.

\section{CE contemporary (safety) risks 2018: MDV-1 circular redesign and foreseeable concept}

Over the past decade, Circular Economy Principles have been developed. The necessity of a circular economy has been highlighted by many, but perhaps most convincingly by the Ellen McArthur foundation [10]. The foundation describes the circular economy as a system that is restorative or regenerative by intention and the outcome must be achieved by eliminating waste through the superior design of materials, products and systems. Remanufacturing is a key strategy to substantially reduce $\mathrm{CO} 2 / \mathrm{GHG}$ emissions (Green House Gas). Except these reductions, at the same time the CE-focus is on renewable energy, renewable raw materials and 'happy people'; new business- and value chain models must be developed. After the Paris Climate Agreement (2016), the concept of Circular Economy (CE) is currently high on the socio-political agenda with (inter)national climate goals (2030: $50 \%$ CO2 $\downarrow, 2050: 100 \%$ $\mathrm{CO} 2 \downarrow$ ). For the CE-performance, the (re)design subjects are beyond the fishing vessel boundary itself. 
More on political and organizational level than SME level. However, from the skipper-owner perspective, the key CE-chain factor is the fishing vessel with an optimal earning capacity in catching and landing good quality fish and to what extent/costs can the vessel be resilienceproof (re)designed? After the linear, safety SHE- and quadruple-P CSR design approach, the new resilience design goals must be $\mathrm{CE}$ driven. Then the general CE principles have firstly to be translated in practical (re)design drivers with challenging targets (Horizon 2050) as successfully experienced in the MDV design- and building process. The Kindunos safety-, MDV-1 quadruple -P design-drivers must be followed by the new triple-Z CE drivers (Zeroemissions, Zero-waste, Zero accidents on board; Table 1).

Table 1. Circular Economy principles, CE-drivers and CE-design targets

\begin{tabular}{|c|c|c|}
\hline Circular Economy (CE) principles & CE- drivers 2018 & CE-targets 2050 \\
made to be----->made again & triple-P & triple-Z \\
\hline Energy saving & Planet & $0 \%$ CO2 \\
\hline Reducing waste & Profit & $0 \%$ waste \\
\hline Happy people & People & $0 \%$ accidents \\
\hline Retaining value & End-of-life value & $100 \%$ recycling, re-use \\
\hline Prolonging lifespan & lifetime & 40 yrs. \\
\hline
\end{tabular}

A design shift should be made to integrate the CE- principles and CE-goals in the early stages of fishing vessel design. Based on merchant shipbuilding EEDI-index algorithms (energyefficient design indexes), the CEDI-index methodology has been developed, holistically integrating the three crucial CE-resilience-redesigning aspects at the same time: vessel decarbonization, vessel recycling, fish processing automation and gaining more public support. Instead of only making vessels sustainable through energy saving (merchant shipping), also the degree of recycling and the degree of on-board automation must be equally taken in consideration. To comply with these CE-targets, the holistic CEDI-index design approach have been drafted and already validated with four MDV-1 CE redesign concepts. In these redesign-concepts the level of de-carbonization (Planet, CEDI-index matrix I)), level of recycling (Profit; CEDI-index matrix II) and level of automation (People; CEDI-index matrix III, Table 2) is gradually increased. In the PhD papers (2017-present), the scientific design development has been peer-reviewed and worldwide published, so that SME can foreseeably manage the new CE-complexities in a profitable way [12-15]. 
Table 2. CEDI-index matrix III fish processing-automation, from MDV-1 -->MDV 1-Circular

\begin{tabular}{|c|c|c|c|c|c|}
\hline $\begin{array}{l}\text { CEDI } \\
\text { ranking } \\
\text { Solution } \\
\text { matrix III }\end{array}$ & $\begin{array}{c}1 \\
\text { DD }\end{array}$ & $\begin{array}{c}2 \\
D E\end{array}$ & $\begin{array}{c}3 \\
\text { LNG/BIO-E }\end{array}$ & $\begin{array}{c}4 \\
\text { LH2-CELL }\end{array}$ & $\begin{array}{c}5 \\
A E\end{array}$ \\
\hline $\begin{array}{l}\text { MDV-1 } \\
\text { redesign CE- } \\
\text { concepts }\end{array}$ & $\begin{array}{c}\text { Twin-rig } \\
\text { beamer } \\
(O D 6)\end{array}$ & $\begin{array}{c}\text { Twin-rig } \\
\text { sterntrawler } \\
\text { (MDV-1 to 5) }\end{array}$ & $\begin{array}{c}\text { Twin-rig } \\
\text { sterntrawler } \\
(\mathrm{MDV}-5-10)\end{array}$ & $\begin{array}{c}\text { Twinrig } \\
\text { stern trawler } \\
\text { (MDV 10- 20) }\end{array}$ & $\begin{array}{c}\text { Twinrig stern } \\
\text { trawler } \\
\text { (MDV- Circular) }\end{array}$ \\
\hline $\begin{array}{l}\begin{array}{l}\text { Level of } \\
\text { automation }\end{array} \\
\text { Fish process } \\
\text { sing }\end{array}$ & $\begin{array}{l}\text { Benchmark } \\
\text {-fish process. } \\
\text { forward } \\
\text {-handsorting } \\
\text { species } \\
\text {-hoppers } \\
\text {-transport } \\
\text { conveyors } \\
\text {-batch } \\
\text { washing } \\
\text {-pre-cooling }\end{array}$ & $\begin{array}{l}\text { Idem 1) but } \\
\text {-fish proc. } \\
\text { amidships } \\
\text {-mechanical } \\
\text { flatfish fish } \\
\text { gutting, } \\
\text {-mechanical } \\
\text { flatfish sorting } \\
\text {-mechanical } \\
\text { weighing and } \\
\text { filling boxes }\end{array}$ & $\begin{array}{l}\text { Idem 2) plus } \\
\text {-stunning } \\
\text { module } \\
\text {-version } 2.0 \\
\text { gutter and } \\
\text { grader }\end{array}$ & $\begin{array}{l}\text { Idem } 3 \text { ) plus } \\
\text { gutter-grader } \\
\text { and semi- } \\
\text { autonomous } \\
\text { storage fish } \\
\text { boxes }\end{array}$ & $\begin{array}{l}\text { Autonomous } \\
\text { fish processing } \\
\text { and storage }\end{array}$ \\
\hline $\begin{array}{l}\text { SHE beamer } \\
\text { solutions } \\
\text { (table 1) }\end{array}$ & $40 \%$ & $70 \%$ & $80 \%$ & $90 \%$ & $100 \%$ \\
\hline $\begin{array}{l}\text { degree of } \\
\text { automation }\end{array}$ & $10 \%$ & $30 \%$ & $50 \%$ & $75 \%$ & $100 \%$ \\
\hline $\begin{array}{l}\text { Investments } \\
\text { Percentage }\end{array}$ & - & parent vessel & $\begin{array}{c}100.000 \\
2 \% \\
\end{array}$ & $\begin{array}{c}300.000 \\
6.5 \% \\
\end{array}$ & $\begin{array}{c}1.000 .000 \\
22 \%\end{array}$ \\
\hline Estimated & $6.5 \mathrm{M}$ euro & $4.5 \mathrm{M}$ euro & 4.6 $\mathrm{M}$ euro & $5 \mathrm{M}$ euro & 5.5 Meuro \\
\hline
\end{tabular}

The ultimate CE-goals are autonomous fish processing decks and fish hold-box handling. There are already good handling and storage systems on shore, albeit these systems aren't yet marine proven. Although the degree of automation is rapidly increasing, a fully autonomous fishing vessel with foreseen non-occupational accidents, is yet out of the realm of possibility and not yet a main cost driver. It will be a matter of decennia before a fully remotely controlled fishing platform will be viably operated and without any occupational accidents on-board.

However to-day, the socio-,economic and technical fishery systems are constantly changing, aggravated by the political climate- and energy-transitions Regarding the new build investments, the estimated automation-investment must have realistic payback times, once better landed fish prices are being paid to the fishermen through better landed, high quality fish in the new fishery value chain (CE-fish2dish). With the CEDI-index matrix approached, the safe- $\&$ sustainable working conditions are fully guaranteed. Additionally controlled, by making use of current EU mandatory, interactive risk assessment web tools (OiRA). With such a tool on board, an appropriate risk assessment process and safety awareness take constantly place. Starting with the identification and evaluation of workplace risks and taking preventive (resilience) actions through transparent monitoring and reporting. As with the Kindunos safety-integrated matrices (1-10), the relevant CEDI-index matrices 1-3 are not a blueprint but a supportive pre-design tool. Where the Kindunos roadmap lead towards safer SHE beamer conditions, leads the CEDI (re)design system approach to CE fishery systems, resilient-proof without too high modification/refit costs in the near future. 
Regarding new fishery value chains, MDV-start-up discussions are underway for further flatfish chain integration. In which fishermen $\&$ the processing industry are working closely together supplying good quality fresh fish (fish2dish, licence2fish). With such a chain approach, the sector can anticipate the new EU eco-system regulations and EU political changes (Marine Strategy; Food Safety, Landing Obligation undersized species, Brexit). The new CE resilience redesigning system deals with the economic \& ecological survival of the current sea fishing industry with intrinsic safety aspects and good residual value at the end-oflifecycle as well as sound public support.

\section{Maritime resilience from dual-SME business and designers perspectives}

From a scientific resilience point of view, in the 90 s the Kindunos methodology was the first successful example of a safety systems redesigning approach with bèta $\&$ alpha key-redesign drivers The so-called 'hard'( $(\beta)$ and 'vague' $(\alpha)$ design requirements were ad-hoc integrated in the basic fishing vessel design (table 1). Where in the safety-science domain, alpha-resilience approaches are more common. At the time of CSR, safety/well-being \& sustainability $(\gamma)$ had to be further integrated in a disruptive MDV-1 new design with triple-P design drivers and safety as intrinsic asset (table 2). Especially for small to medium sized fishing vessels (24 $40 \mathrm{~m}$ ), the human and societal factors are the SME resilience (re)design drivers and in the (re)design equally important as energy saving and recycling (table 3). For small-medium sized enterprise (SME) it is a complicated matter in making the right choice in (partial) engineering solutions, even more complex due to the uncertain climate- and energy transitions and rapid development of new green technologies. An important success factor in the MDV design process appeared to be the intensive cooperation of the MDV-1 (research) skipper/coowner (SME) and the subject matter expert (SME). The subject matter expertise was brought in by the MDV innovation manager by stimulating and guarding the innovations to achieve the agreed MDV design goals. Additionally, the MDV innovation manager went regularly onboard to check the MDV innovations during practice and have stimulating discussions with the skipper/crew for possible design improvements for the follow-up MDV-vessels. Already $6 \mathrm{MDV}$-type vessels have been delivered and 6 are being committed, including the MDV-2 and 3. The progress reports were reported to the MDV foundation and MDV-1 shipbuilders as well (ref). Through this cooperation and reporting, the gap between theory and practice was bridged, on corporate-, sector and organizational level. The MDV foundation communicated regularly to all stakeholders, on sector-, ministry, EU- and public level (symposia, fishery meetings, magazines, newspapers, TV and open access MDV website).

\section{Resilient (re)designing to anticipate the new $\mathrm{CE}$ challenges}

As firstly applied in the successful MDV-1 design process, sustainability requirements lead to disruptive (design) technologies, new business models and entrepreneurial competences (ref). The new business performance systems are intrinsic safe, while safety has to be considered as a strategic asset in the new CE-value chains. Such changes in the socio-economic environment also requires disruptive changes in safety thinking and scientific interests [1622]. Traditional scientific constructs run short in explanatory potential (ref). The Kindunos methodology has been evolved from a linear safety-, via a triple-P sustainable-, towards a triple-Z circular redesigning approach (Zero-emission (Planet), Zero waste (Profit), Zero accidents on board (People). In which future-proof business models for flatfish fishing systems are decisive resilience characteristics, so that (near)future human-, SME business behavior and socio-political support can be better foreseen and cost-efficiently anticipated on. 
The successful MDV-1 design approach and success factors appeared to be transparent design goals, multi-disciplinary cooperation, private -public financing and sector-public support. To anticipate the new CE challenges, an organic and holistic redesign model is necessary, far beyond safety. Regarding working conditions, further automation must be foreseen with gradually increasing levels of automation (CEDI-index matrix 3, table 4). With the CEDIindex oriented solution matrices (1-3), the SMEs and designers can anticipate the upcoming $\mathrm{CE} / \mathrm{EU}$ legislation in an early design phase with preliminary sustainable designs (safety,fish2dish, license2fish). This means resilience-(re)designing is not only a circular problem solving approach but also reflects on a higher knowhow level of the skipper \& crew and broad commitment on sector-, political- and public level. A bad resilient-innovation lesson learned, is the current Dutch-EU pulse fishing file and possible EU ban on sustainable fishing gears (EU "trilogue" discussions). EU parliament and other countries are against this innovative flatfish gear, proven sustainable (50\% CO2 $\downarrow$, selective) and fully scientifically supported [25]. Possibly, the (inter)national resilience operational approach started to late and was far from transparent with unjustified twitter- and internet reporting (framing, fake news, fabricated facts) by rival fishermen abroad (F,B) and NGOs (F). Fishermen, Dutch public and Dutch NGOs are in favor of these innovative fishing gears, esp. from a planet (selective) and profit (better quality fish) and people (safer gear handling) point of view. The fishermen and Dutch public don't understand the ongoing political discussions. To prevent such ad-hoc discussions, the triple-P predesign- and innovation drivers should be extended with another P, the Public-perception. Then these quadruple-P drivers must holistically be taken in consideration in design spirals. Nowadays, existing, new regulations and public perception could not be neglected and have a high (re)design impact on the fishery performance systems.

Through the new resilient (re)design methodologies (Kindunos, MDV-1, CE-concepts) and developed supportive tools (solution matrices), SMEs, designers and stakeholders do get more insight how to cost-efficiently integrate the new (re)design challenges and what the organizational, public consequences could be. The linear Kindunos safety-problem solving oriented approach (90s) and the disruptive MDV-1 pilot vessel (2015) are good examples how socio-political commitment can be achieved. Besides, the three resilience approaches are addressing the human behavior $(\alpha)$ in a structural and objective way, making use of new green technical requirements $(ß)$ and comply with the new socio-economic requirements $(\gamma)$. SHE, business models and public acceptance are the new change drivers. Achieving the existing (SHE, CSR) and new requirements (CE) require a deep understanding of the North Sea fishery systems, the evolving green technologies and socio-political drivers. Because of this complexity and the regional bound SME sector, intensive cooperation with designers, fishermen, administrators and operational actors were prerequisite. The design and launching of the MDV-1 pilot vessel (2015) appeared to be a good example of corporate and sectoral, public-private cooperation with input of SMEs, fishermen and supplying companies. The establishment of a multi-disciplinary MDV foundation with a subject matter expert (SME) was decisive with constantly open access knowledge transfer and publication of the results in journals and magazines. In the current transition phase, SMEs, designers and sector aren't interested yet in a blueprint but a CE (design)roadmap to anticipate the upcoming climaterequirements, yet too vague for SMEs with new building plans. At the SHE time, the sector was also not interested in new beamer designs because of the existing young fleet and the SMEs were more interested in a redesign roadmap to substantially decrease the common occupational accidents (Figure 1,2). 
Based on the scientific description of the MDV-1 design process the near-future climate- and energy targets have been further integrated in a CE problem solving approach. For this new triple- $Z$ design drivers have been developed. As proof of concept and based on the CEDI solutions matrices, four circular-sustainable MDV-1 re-design concepts have been developed. In which the Beamer-2000 SHE shortcomings and MDV-1 (crew) recommendations have been be fully dealt with, even aiming at all-renewable energy (Zero-emission), renewable raw (construction) materials (Zero-waste) and with happy people on board (Zero occupational accidents). For SMEs their surviving and future profits are leading, while for the sector and ministries the survival of a sustainable fishing industry is addressed.

Nowadays, more stakeholders are interested in how safety, and the circular economy principles can be built in new defined resilience systems. Not only in the fishing vessel redesigning, but also towards $\mathrm{CE}$ fish value chains. Such an effort requires disruptive and technologically innovative resilience engineering at SME and sectoral level (MDV foundation) rather than adaptation at a strict corporate or organizational level. It requires an integration of engineering design methodologies, organizational changes and transition management strategies. By integrating the required safety-and sustainable adaptations $(\alpha-\beta-\gamma$ drivers) and future proof business models, the design trajectory is research intensive. For commercial design parties this kind of exercise is not economically feasible, but with the establishment of a multi-disciplinary foundation and public subsidies this can be solved. This integrative top-down (new knowledge and governance based) \& bottom-up (corporate, sector expertise) approach facilitate foresight on future use and exploitation of fishing vessels in a life cycle approach. In the current fishing vessel design spiral also societal acceptance must be cyclically integrated. Without too much R\&D, also SME will get a future-proof vessel. Making them less dependent on political, business and socio-economic changes as well as NGO fabricated fake facts on the short and long term. Actually giving fully substance to the intrinsic CE-sustainability requirements and holistic design concepts (Horizon 2050).

\section{Acknowledgements}

The authors would like to thank the MDV foundation for the opportunity of being their innovation manager and introduction of green technologies in the Dutch fisheries. Also, sincere thanks to the MDV-1 crew for their stimulating on board discussions, keeping me with 'two feet on the fishery deck'. Last but not least, sincere thanks to professor Hans Hopman, professor John Stoop (TU Delft) and professor Peter Groot Koerkamp (WUR) for our stimulating discussions bridging the gap between fundamental research and practical utilization and SME resilient.

\section{REFERENCES}

[1] Stoop, J.A (1990).Safety and the Design Process. Delft: Doctoral Thesis TU Delft. ISBN 90-9003301-7

[2] Stoop J.A, Veenstra F.A. (1992) Information technology in the fishing industry. Amsterdam: Elsevier Science Publishers, Computer applications in ergonomics, occupational safety and health; pp 219-226

[3] Stoop, J.A.; Veenstra, F.A.(1993). Towards a safety integrated design method. The Hague: Proceedings 9th International Conference on Engineering Design ICED 93, August 17-19, 1993. 
[4] Stoop, J., Dekker, S (2010) Accident modelling: from symptom to system. Human factors and Ergonomic Society EU; Annual meeting, 14016 Oct. , Linköping ,Sweden.

[5] Veenstra, Frans (1999). Accident prevention onboard Dutch Fishing vessels Lorient Dutch-France workshop,23-25 April 1999

[6] Veenstra ,Frans. Stoop, John (1990). Beamer 2000; Safety integrated (re)designing, the Kindunos method. The Hague: CIP-DATA Royal Library, ISBN 90-74549-02-0 (subject heading: Beamer 2000)

[7] Veenstra, F.A., Mul, N. (1991). IQAS flatfish processing on board beamer 2000. Ancona: ICES, 22-24 april 1991.

[8] Veenstra, Frans. Brinkman, Rick (1995). Stern Trawler 2000, a new approach designing on points sustainable aspects: working conditions, HACCP quality control of environment. HSB International; VOL 44-No1; pages:51-53.

[9] Veenstra, F.A. (2002). Dutch newbuildings after the 2000 re-design requirements. Fishing News International, Good Gear Guide 2002-new vessels. ISBN:0-9518579-9-1 ;pgs25-31

[10] Ellen Macarthur foundation. https://www.ellenmacarthurfoundation.org/circulareconomy/interactive-diagram

[11] Veenstra, Frans. (2016). MDV-1,from innovative IDEA (2006) to Ship of the Year (2016) (in Dutch). https://masterplanduurzamevisserij.nl/nl/kennisbank/onderzoek/publicaties.

[12] Veenstra, F.A, Hopman,J.J, Stoop, J.A.A.M (2017). Multicriteria Fishing Vessel Design Methodology .USA Journal of Fisheries and Aquaculture (IJFAR); Volume 2017, Issue Oct. 06 .

[13] Veenstra, F.A, Stoop, J.J.A.M, Hopman, J.J. (2018). Sustainability in fishing vessel design process 1988-2018 MARTECH 2018, Lisbon 4th international conference on maritime technology and engineering 7-9 May, Lisbon Portugal

[14] Veenstra, F.A, Stoop, J.A.A.M and Hopman, J.J (2018) CEDI sustainability-ranking in fishing vessel design process; WMTC18, f-180612-259, World Maritime Technology Conference; Dec. 5-7, 2018

[15] Veenstra F. A., Stoop J.A.A.M and Hopman J.J (2019) 'Cedi-Index Validation In circular Fishing Vessel Design Process', International Journal of Current Advanced Research,(IJCAR) 08(01), pp. 16776-16782. http://dx.doi.org/10.24327/ijcar.2019.16782.31

[16] Stoop, J (2017/1) Poised to adapt. Enacting resilience potential through design, governance and organisations; 7th REA, 26-29 June, Liège, Belgium.

[17] Van der Hoven, J (2013) Value sensitive design and responsible innovation. Whiley online library. https://doi.org/10.1002/9781118551424.ch4

[18] Vincenti, W (1990) What engineers know and how they know it. Analytical studies from aeronautical history. John Hopkins University Press. 
[19] Woods, D,D. (2006). Essentials characteristics of resilience In E.Hollnagel, Woods,D.D, leveson, N (Eds.), Resilience engineering: concepts and precepts (pp 21-33). Aldershot, UK Ashgate

[20] Hollnagel, E, Paries, J, Woods, D.D, Wreathall, J (2011).Resilience Engineering in Practice, a guidebook Ashgate studies; ISBN: 978-1-4094-1035-5

[21] Morel, Gael, Chauvin, Christine (2006) Towards a new state of resilience for the sociotechnical system of the sea fishing industry, Safety Sciences, 44, pp 599-619

[22] Janse, B. (2018).Cyclic Innovation Model (CIM) by A.J. Berkhout. Retrieved [march 2019] from ToolsHero: https://www.toolshero.com/innovation/berkhout-cyclic-innovationmodel-cim/

[23] Lloyds Register, UMAS (2017). Zero-Emission-Vessels 2030. info.lr.org/zero2030

[24] SSPA TEM MariTerm AB (2004) LCA ship, a life cycle analysis program for ships. http://www.mariterm.se/wpcontent/uploads/2016/08/Final-report-LCA-ship.pdf

[25] WUR (2018) https://www.wur.nl/en/Dossiers/file/Pulse-fishing.htm http://www.bloomassociation.org/en/wp-content/uploads/2018/01/electric-fishingadvocacy.pdf 